\title{
Mononuclear Phagocytes in Rheumatoid Arthritis Patients and their Relatives - Family Similarity
}

\author{
Marina I. Arleevskaya ${ }^{*}, 1$, Aida G. Gabdoulkhakova ${ }^{1}$, Julia V. Filina ${ }^{1}$, Aleksey I. Zabotin ${ }^{2}$ and \\ Anatoly P. Tsibulkin ${ }^{1}$
}

\author{
${ }^{I}$ State Medical Academy of Postgraduate Education, ${ }^{2}$ Institute of Biochemistry and Biophysics. Russian Academy of \\ Science, Kazan, Russia
}

\begin{abstract}
The aim of this work was to study the peripheral blood monocyte functions in patients with advanced RA and their predisposed to RA relatives in comparison with those in women, not hereditary tainted with autoimmune diseases (donors). In groups comprising 24 RA patients, 24 relatives, and 24 donors the following monocyte functions were assessed: engulfment and digestion (radioisotope method); release of lysosomal glucuronidase in response to opsonized zymosan (fluorescent method); reactive oxygen species (ROS) generation (chemiluminescence), and serum levels of proinflammatory cytokines (ELISA). The monocyte specific feature in patients and their relatives is chiefly extracellular digestion due to the delayed engulfment. The digestive activity, probably inhibited in relatives, is increased in advanced RA. ROS generation by the cells and serum levels of TNF-alpha and IL-1-beta are abundant both in the patients and their relatives.

High levels of pro-inflammatory cytokines, presumably, of monocyte origin, and increased levels of stimulated ROS generation may be due to the priming and prolonged activation of monocytes in relatives.

Conclusion: We show for the first time that the functioning of circulating mononuclear phagocytes in the assumed to be healthy predisposed to RA individuals differs from that in the healthy people not hereditary tainted with autoimmune diseases and in general resembles the functioning of the cells in the patients with advanced RA.
\end{abstract}

Keywords: Rheumatoid arthritis, relatives, monocytes, phagocytosis, cytokines.

\section{INTRODUCTION}

For long the role of monocyte - macrophage system in the pathogenesis of rheumatoid arthritis (RA) remains an attractive research focus. Indeed, these cells are present in prominent number in the inflamed synovial membrane and at the cartilage - pannus junction since the very early stages of the disease [1-3]. Joint tissue macrophages are critically involved in the pathogenesis of RA. They are the primary source of the proinflammatory cytokines and chemokines in the inflammatory sites and contribute to the cartilage and bone destruction (reviewed by Bresnihan B. and by Ma Y., Pope R.M.) [3, 4]. The number of these cells in synovial lining layer at baseline correlates with the number of new erosions on radiographs of the hands and feet 1 year later and with the disease activity on all the stages of RA development [3,5].

As it was borne out again (this time - with the help of monocyte scintigraphy after the reinfusion of the labeled cells to the RA patients), the macrophages of the joint inflammatory sites are of vessel bed monocyte origin [6]. It is essential for the RA pathogenesis, that circulating monocytes are the precursors not only of tissue and inflammatory macrophages in rheumatoid joints, but of dendritic cells and osteoclasts as well, both known to be the

*Address correspondence to this author at the State Medical Academy of Postgraduate Education, Kazan, KSMA, 11, Mooshtary str., Kazan, 420012, Russia; Tel/Fax:+007 (843) 2383998; E-mail: marleev@mail.ru important players in the disease development (reviewed by Kinne R. W.) [7].

It should be pointed out that by no means blood vessel monocytes should be interpreted as simple precursors of various joint tissue cells - the RA pathogenesis players. There is the well known evidence of a specific condition of the circulating monocytes - spontaneous production of prostanoids and prostaglandin $\mathrm{E}_{2}$, cytokines, soluble CD14, as the examples, and, more generally, gene activation with a pattern closely resembling the synovial activation pattern (reviewed by Kinne R.W., et al.) [8]. So, to the review author's opinion, the circulating monocytes in RA appear to be preshaped in a "rheumatoid" phenotype before they entry into the inflamed synovial tissues. There is also the evidence of alteration of bone marrow myeloid precursors in RA patients [8]. So, the "rheumatoid" phenotype of the circulating monocytes may be a result of the specific exposure of their bone marrow precursors or the epiphenomenon of a central differentiation defect.

The data presented in this publication are the part of the long-term (more than 10 years) cohort study of rheumatoid arthritis (RA) and common infections relationship. The undertaken long term clinical monitoring of the RA patients and their first degree maternal relatives, generally accepted to be predisposed to the disease $[1,11]$, showed that these individuals suffer from frequent and prolonged common infections that may a result of antiinfectious defense insufficiency, namely of it's innate component (in press). 
Here it is timely to recall the following well known facts. First, along with neutrophils monocytes - macrophages are key actors in antiinfectious host defense [10]. Second, innate immunity, with macrophages playing a central role, is critically important in the pathogenesis of RA $[9,12]$. Third, in the overwhelming majority of the RA cases the disease sneaks up insensibly, so the mentioned above "rheumatoid" phenotype of monocytes in predisposed to the disease individuals may develop long before the first joint symptoms as a result of frequent and prolonged common infections in particular.

Thus, the comparison of the monocyte functioning in RA patients and in their predisposed to the disease relatives (the cells of women, not hereditary tainted with autoimmune diseases, being a control), may be useful for the solving the problem of RA provocation.

\section{MATERIALS AND METHODOLOGY}

The research project was approved by the Kazan State Medical Academy Ethics Committee (State registration N 01200502513) and was conducted in accordance with the declaration of Helsinki and the Russian National Health and Medical Research Council statement on human experimentation.

\section{Subjects}

For the current experimental series we have selected 24 female patients (Ps), aged 45,6 $\pm 12,8$ years with advanced RA (7,3 $\pm 3,5$ years of disease duration, Table 1), 24 first degree maternal relatives (Rs) of these patients (average age $39,9 \pm 10,6$ years) and 24 assumed to be healthy women without inherited predisposition to autoimmune diseases had an average age 40,7 $\pm 15,7$ years (control group, Ds).

Groups of RA patient, their relatives and donors underwent routine clinical and paraclinical examination to reveal the inflammatory syndrome (ESR, leukocyte count, $\mathrm{C}-\mathrm{RP}$, fibrinogen), the autoimmune syndrome (IgM-, IgG-, IgA- rheumatoid factors, anticitrulline antibodies, anticardiolipin antibodies, antiDNA antibodies, complement, circulating immune complexes, immunoglobulins), as well as a magnetic resonance imaging (relatives) and a X-ray photograph (RA patients), microbial analysis - bacterial seedings of nasopharyngeal, urinal, vaginal and gut common microflora.

All the Ps received DMARD supporting therapy: methotrexate $19(79,2 \%)$, leflunomide $4(16,7 \%)$, and $1 \mathrm{P}$ sulfasalazine $(4,1 \%)$, intraarticular corticosteroids during exacerbation of RA ( $\sim 40 \%$ of P). In the RA group selected for the current experimental series there were no cases of the evident relationship between infectious syndrome development and specific immunosuppressive therapy (exclusion test).

The selected group of first degree female relatives comprised of 17 daughters, 6 sisters and 1 woman, who happened to be both a sister and a daughter of an RA patient. Fifteen $(62,5 \%)$ of them had shared epitope (HLA DRB $1 * 04,04 ; * 04,01 ;$ or $* 04$, or $* 01)$ in genome, rheumatoid factors were transiently revealed in $13(54,2 \%)$ while antibodies against citrullinated peptides in $12(50,0 \%)$ of them.
Not a singlee diagnostic laboratory RA marker or a positive paraclinical sign of inflammation was revealed in the control group.

Methods. The cell and serum samples were taken for investigations in the period between the infectious episodes in the absence of clinical signs of infection (in all groups) and with no paraclinical signs of inflammation (in relative and control groups).

Mononuclear Phagocyte (MP) Isolation Peripheral blood MPs were isolated using a universally accepted method of Ficoll - Urografin density gradient separation [13].

Engulfment and Digestion Functions of MP were estimated within 24 hours using a radioisotope method. We reproduced the classic experiments, performed by J. Schmidtke and E. Unanue with some our modifications [14]. The object of phagocytosis (OP) - Staphylococcus aureus strain Wood was grown in the media with ${ }^{14} \mathrm{C}$ - labeled amino acids and opsonized with pooled native sera (blood group IV). The OP suspension was added to MP suspension to provide $10^{3}$ microbial bodies per cell with the following incubation after that at $37^{\circ} \mathrm{C}$ for 30 minutes, and after that the unbound material was removed by centrifugation. Then the cells were washed twice.

The first cell measurements were done immediately following the 30 minute incubation, the next - in 2, 4, and 24 hours of incubation at $37^{\circ} \mathrm{C}$. The cells incubated for further 2, 4 and 24 hours were then centrifuged and washed twice to remove all accumulated products of digestion from suspensions. Thus, each tested MP sample contained only those digestion products that had accumulated within a certain time period. The supernatants received following the first 30 minutes of incubation with labeled bacteria contained OP both unbound to the cells and already degraded ones. Therefore the intensity of digestion of labeled bacterial proteins by the cells to low-molecular weight peptides (LMP) during this time was assessed as a value difference between the radioactivity of cell suspension supernatants and bacteria suspension supernatants after treatment of them both with $20 \%$ trichloroacetic acid. As to high molecular weight degraded products (HMP), this value was not taken into consideration, since it was not possible to determine the parts of OP, unbound to the cells and those already digested.

After cell sedimentation the following samples were measured using Beta analyzer (POMA, Kiev, Ukraina): (a) the total cell - bound radioactivity of the label; (b) the intracellular radioactivity of the label (following the removal of surface membrane proteins by trypsin treatment); (c) the radioactivity of the supernatants (HML and LMP - bound label); (d) the radioactivity of the LMP - bound label (after HMP precipitation by $20 \%$ trichloroacetic acid). The measured values were expressed in CPM - count per minute. Under the selected experimental conditions the MP counts were not essentially decreased in the samples, and their viability estimated by trypan blue staining was $95-98 \%$.

FITC-labeled aggregated human immunoglobulin (Agg-Ig-FITC) engulfment was estimated in 30 minutes after incubation of MP with Agg-Ig-FITC $(1,25 \mu \mathrm{g} / \mathrm{ml}$ of protein per $10^{6}$ cells). After the removal of unbound Agg-Ig- 
Table 1. Characteristics of the Patients in the Advanced RA group $(n=24)$

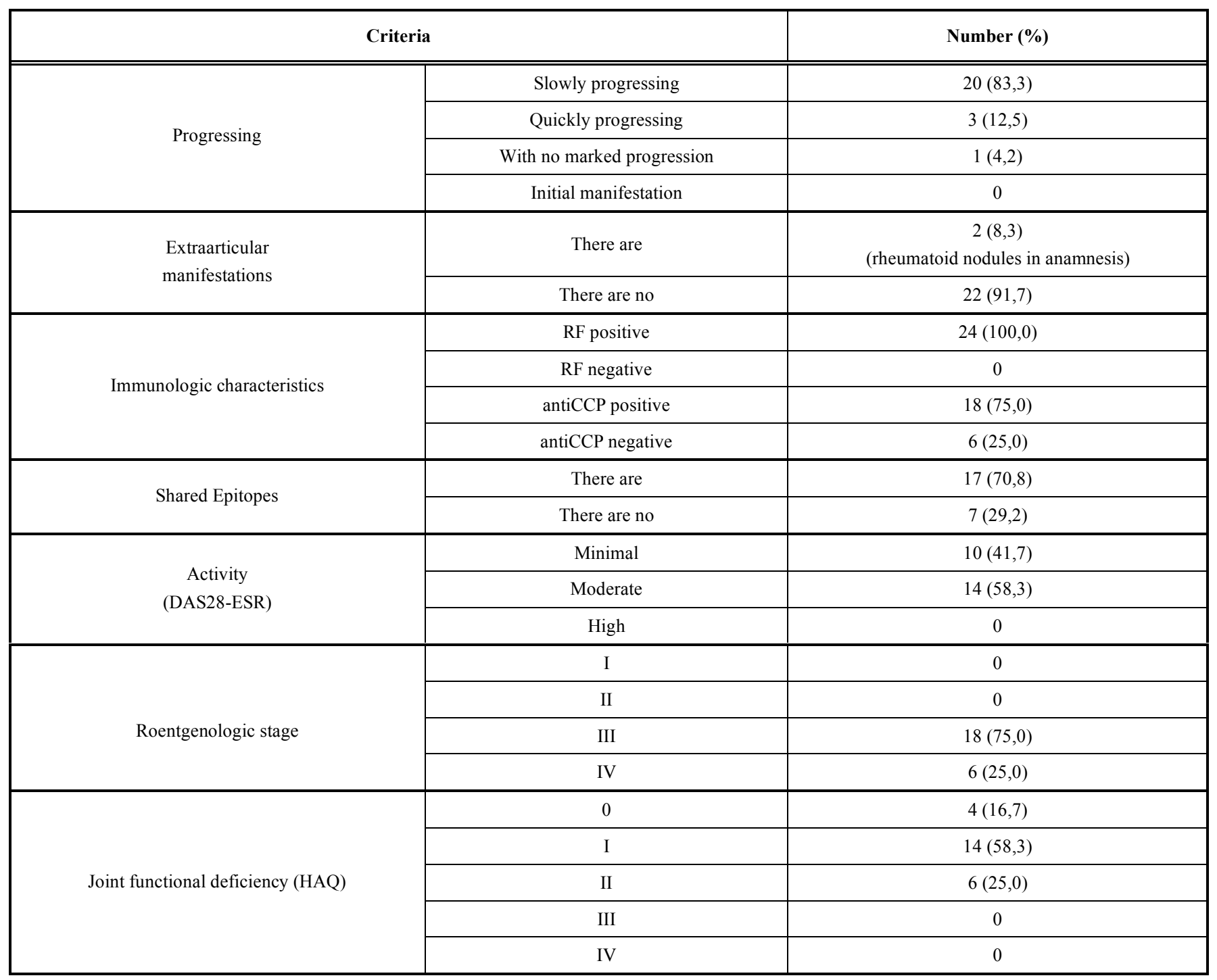

FITC and membrane associated proteins by trypsin treatment of the cells the fluorescence of intracellular Agg-Ig-FITC was measured $\left(\lambda_{\mathrm{ex}}=492 \mathrm{HM}, \lambda_{\mathrm{em}}=518 \mathrm{HM}\right)$, using a MPF 44B spectrofluorimeter (Perkin Elmer, USA).

Release of lysosomal glucuronidase from MP in the first 30 minutes of the cell incubation with opsonized zymosan (OZ) was estimated by fluorescence of the hydrolysis product of MUF - $\beta$ - glucuronide (Sigma, USA), that is a fluorescent analog of the glucuronidase substrate. Measurements were made using a MPF 44B spectrofluorimeter (Perkin Elmer, USA) at $\lambda_{\mathrm{ex}}=325 \mathrm{~nm}$. The substrate content was defined at $\lambda_{\mathrm{em}}=448 \mathrm{~nm}$, while the product - at $\lambda_{\mathrm{em}}=375 \mathrm{~nm}$. The intensity of glucuronidase release was calculated as the ratio product/substrate fluorescence intensity measured before and $0.5,15$ and 30 minutes after $\mathrm{OZ}$ addition (arbitrary units, au). To exclude the possible cellular uptake of the MUF- $\beta$-glucuronide and its intracellular cleavage we sedimented the cells after incubation with fluorescent probe and measured the fluorescence of the pellets and supernatants. These control experiments showed, that the substrate and the product were only revealed in the supernatants, but not in the cells.
Treatment of the MPs with phagocytosis modulators. In some experiments we treated the MPs with $50 \mu \mathrm{M}$ vinblastine (Sigma, USA) for 30 minutes, or $0,1 \mathrm{mM}$ isoniazid (Sigma, USA) for 1,5 hours $\left(25^{\circ} \mathrm{C}\right)$ before $\mathrm{OZ}$ addition. The intact MPs (as a control) were incubated without modulators but in the same conditions.

Reactive oxygen species (ROS) generation by the MPs was estimated by luminol-dependent chemiluminescence technique. Chemiluminometer designed at the KSMA by Dr. Zinkevich O.D. was used. Real time registration was performed every $4 \mathrm{sec}$ in the thermostated chamber with continuous mixing of the cell suspension (sample volume was $3 \mathrm{ml}$, cell density $-3 \times 10^{6}$ per $\mathrm{ml}$, and concentration of $\mathrm{OZ}$ was $0.1 \mathrm{mg} / \mathrm{ml}$ ). The following parameters were measured (arbitrary units, au): the spontaneous level of ROS production, total ROS production estimated as an area under the curve of time - chemiluminescence intensity dependence within 30 minutes after $\mathrm{OZ}$ addition.

Serum cytokine levels were measured by ELISA method using monoclonal antibodies against tumor necrosis factor 
alpha (TNF-alpha) and interleukin 1 beta (IL-1beta) ("Vector -best", Russia).

Statistic analysis was made using with Student's t-test for dependent samples, Mann - Whitney test, Kruskal Wallis test.

\section{RESULTS}

Reliable differences $(\mathrm{p}<0,05)$ were revealed while studying the process of OP engulfment in all the groups (Table 2, Fig. 1). In the Ds the amount of $\mathrm{C}^{14}$ - bacterial particles engulfed by MPs was almost at the peak in the first 30 minutes of the experiment, while in the Ps the ingestion was maximal at the interval of $2-4$ hours from the beginning of the process. During this time the amount of material engulfed by the D cells was already decreasing (Table 2). Yet, despite the delayed engulfment the patient MPs were already actively digesting during the first half an hour of the experiment (Table 2). The amounts of LMP in cell suspension supernatants of the Ps and the Ds were nearly identical in this time interval. Supernatants obtained 2 hours later with a reliably (Mann - Whitney test, $\mathrm{p}<0,05$ ) lower amount of the engulfed material in the MPs of the Ps showed the same similar values of LMP radioactivity, while the HMP value was 1.5 times higher in this group than the control one (Table 2 ).

In the Rs as well as in the Ps the process of engulfment of the labeled bacterial particles was also slowed down, but it was also distinctly decreased (Table 2, Fig. 1). Yet, in this group as well, the LMP radioactivity in supernatants significantly exceeded the background level after 30 minutes from the beginning of the experiment; 2 hours later it approximated the control value, while the HMP content was even somewhat higher during this time interval (Table 2).

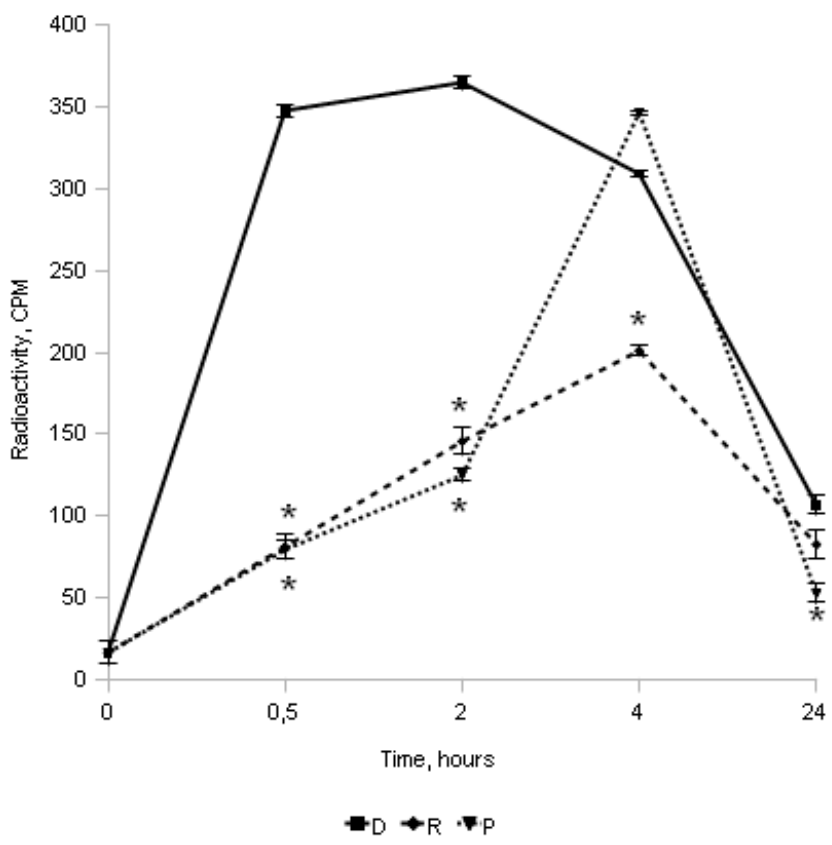

Fig. (1). Radioactivity of the intracellular label in the MP of RA patients $(\mathrm{P}, \mathrm{n}=24)$, female relatives $(\mathrm{R}, \mathrm{n}=24)$, and healthy women donors $(\mathrm{D}, \mathrm{n}=24)$, not hereditary tainted with autoimmune diseases (average values $\pm \mathrm{SD}, *$ - reliable difference when compared to $\mathrm{D}$ group values for the same time interval, $\mathrm{p} \leq 0,05$; complete data are shown in Table 1).

Table 2. The Radioactivity of the Label, Bound with the Mononuclear Phagocytes (MP), Low-Molecular Weight Products (LMP) and High-Molecular Weight Products (HMP) in the Investigated Time Intervals in the Groups of RA Patients (P), Female Relatives (R), and Healthy Women - Donors (D), Not Hereditary Tainted with Autoimmune Diseases, M \pm SD (CPM)

\begin{tabular}{|c|c|c|c|c|c|}
\hline \multirow{2}{*}{ Radioactivity $^{3}$} & \multirow{2}{*}{ Group } & \multicolumn{4}{|c|}{ Time Intervals, Hour } \\
\hline & & 0,5 & 2 & 4 & 24 \\
\hline Intracellular label & \multirow{2}{*}{$\mathrm{D}$} & $348,09 \pm 3.53$ & $365,28 \pm 412$ & 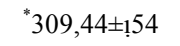 & ${ }^{*} 106,65 \pm 573$ \\
\hline Membrane label & & $1293,89 \pm 9.89$ & ${ }^{*} 687,91 \pm 245$ & 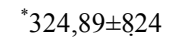 & 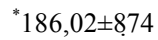 \\
\hline Intracellular label & \multirow{2}{*}{$\mathrm{P}$} & ${ }^{\wedge} 79,28 \pm 591$ & ${ }^{\wedge *} 124,83 \pm 3.92$ & 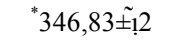 & ${ }^{*} 52,58 \pm 59$ \\
\hline Membrane label & & $1299,63 \pm 523$ & ${ }^{\wedge *} 783,96 \pm 663$ & ${ }^{\wedge} 52,57 \pm \tilde{9}_{11}$ & ${ }^{\wedge *} 121,82 \pm 599_{1}$ \\
\hline Intracellular label & \multirow{2}{*}{$\mathrm{R}$} & ^ $80,96 \pm 7.21$ & ${ }^{\wedge *} 145,62 \pm 821$ & ${ }^{\wedge *} 201,07 \pm 3.12$ & ${ }^{\wedge} 82,48 \pm 843$ \\
\hline Membrane label & & $1637,80 \pm 7.54$ & ${ }^{\wedge *} 803,41 \pm 292$ & ${ }^{\wedge *} 228,68 \pm 153$ & ${ }^{\wedge *} 128,07 \pm 9.71$ \\
\hline \multirow{3}{*}{ HMP } & $\mathrm{D}$ & $1650,3 \pm 101,9^{1}$ & $285,04 \pm 32,8$ & $227,29 \pm 17,6$ & ${ }^{*} 77,46 \pm 9,9$ \\
\hline & $\mathrm{P}$ & $1910,6 \pm 99,9^{1}$ & $443,65 \pm 31,9$ & ${ }^{*} 177,56 \pm 11,5$ & ${ }^{*} 57,43 \pm 12,9$ \\
\hline & $\mathrm{R}$ & $1595 \pm 21,9^{1}$ & $388,61 \pm 23,3$ & ${ }^{\wedge *} 139,05 \pm 10,7$ & 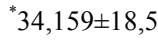 \\
\hline \multirow{3}{*}{ LMP } & $\mathrm{D}$ & $215,79 \pm 10,09^{2}$ & $221,32 \pm 12,6$ & $173,82 \pm 11,7$ & ${ }^{*} 117,48 \pm 19,6$ \\
\hline & $\mathrm{P}$ & $202,43 \pm 9,8^{2}$ & $210,09 \pm 7,09$ & ${ }^{\wedge *} 306,90 \pm 21,8$ & ${ }^{\wedge *} 53,70 \pm 10,7$ \\
\hline & $\mathrm{R}$ & $158,70 \pm 8,9^{2}$ & ${ }^{*} 197,55 \pm 12,7$ & $218,91 \pm 11,2$ & ${ }^{\wedge *} 64,33 \pm 14,6$ \\
\hline
\end{tabular}

${ }^{1}$ The index was not taken into consideration (the explanation - in Materials).

${ }^{2}$ The difference between radioactivity of cell suspension supernatants and that of bacterial suspension supernatants added to the cell samples.

${ }^{3}$ Background radioactivity $16,19 \pm 6,9 \mathrm{CPM}$

* Reliable difference when compared to previous time interval index in the group (Student T-test, $\mathrm{p}<0,05$ )

Reliable difference when compared to D group values for the same time interval (Student's and Mann - Whitney test, $\mathrm{p}<0,05$ ) 
Besides, while estimating the summary values of HMP (except 0-0,5 hour interval index) and LMP within the time of the experiment it turned out, that the digestive activity of the R MPs $(1201,31 \pm 15,68 \mathrm{CPM})$ was reliably (Mann Whitney test, $\mathrm{p}<0,05)$ lower as compared to that in the Ds $(1318,25 \pm 25,67 \mathrm{CPM})$. The highest digestive activity of MP was observed in the P group (1451,76 $\pm 33,02 \mathrm{CPM})$.

Thus, it is of interest to note the fact that despite a small amount of labeled material present inside the cells the MPs of the Ps and, to a lesser degree, - of the Rs were already actively digesting in the first 2 hours of the experiment.

We hypothesized that during this period the digestion predominantly occurs extracellulary due to lysosomal enzyme release into the environment.

To test this hypothesis we studied the release of lysosomal enzyme -glucuronidase - during the interaction between the MPs and OZ. Since the hydrolysis products of the labeled substrate were registered in the cell samples of all 3 groups the extracellular cleavage of MUF-glucuronide is not likely to be a true pathologic process. However, the accumulation of the product in the Ps cell suspensions was reliably (Kruskal-Wallis test, $\mathrm{p}<0,05$ ) more marked at all time periods after $\mathrm{OZ}$ addition (Fig. 2). The intensity of this process in the Rs also reliably exceeded the control values.

To test the suggested model of MP dysfunction in the Ps and the Rs we studied the influence of the well known modulators of phagocytosis - vinblastine, an inhibitor of cytoskeleton assemble, and isoniazid, an agent facilitating lysosome - phagosome fusion, on the Agg-Ig-FITC engulfment and lysosomal glucuronidase release (Fig. 3).

The intensity of fluorescence of Agg-Ig-FITC engulfed by the Ps MPs of the $(114,6 \pm 9,1$ a.u. $)$ and the Rs $(110,5 \pm 8,9$

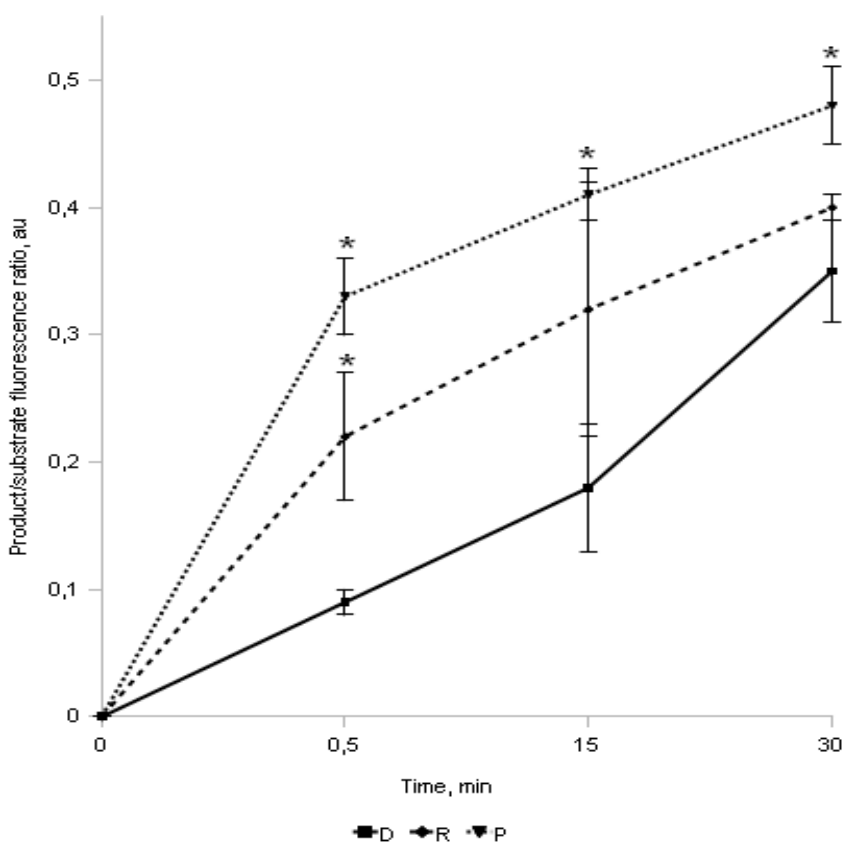

Fig. (2). The intensity of fluorescence of glucuronidase - MUF- $\beta$ glucuronide cleavage products in the MP supernatants of advanced RA patients $(\mathrm{P}, \mathrm{n}=24)$, female relatives $(\mathrm{R}, \mathrm{n}=24)$, and healthy women, not hereditary tainted with autoimmune diseases - donors $(\mathrm{D}, \mathrm{n}=24)$ (average values $\pm \mathrm{SD}$ are shown, * - reliable difference when compared to $\mathrm{D}$ group values for the same time interval, $\mathrm{p} \leq 0,05)$.

a.u.) was reliably lower (Mann-Whitney test, $\mathrm{p}<0,05)$ after 30 minute incubation, than that in the D group $(196,5 \pm 8,7$ $\mathrm{au}$, these results were compatible with the data obtained from the experiments with ${ }^{14} \mathrm{C}-$ Staphylococcus aureus engulfment. Vinblastine treatment resulted in (i) a reliable

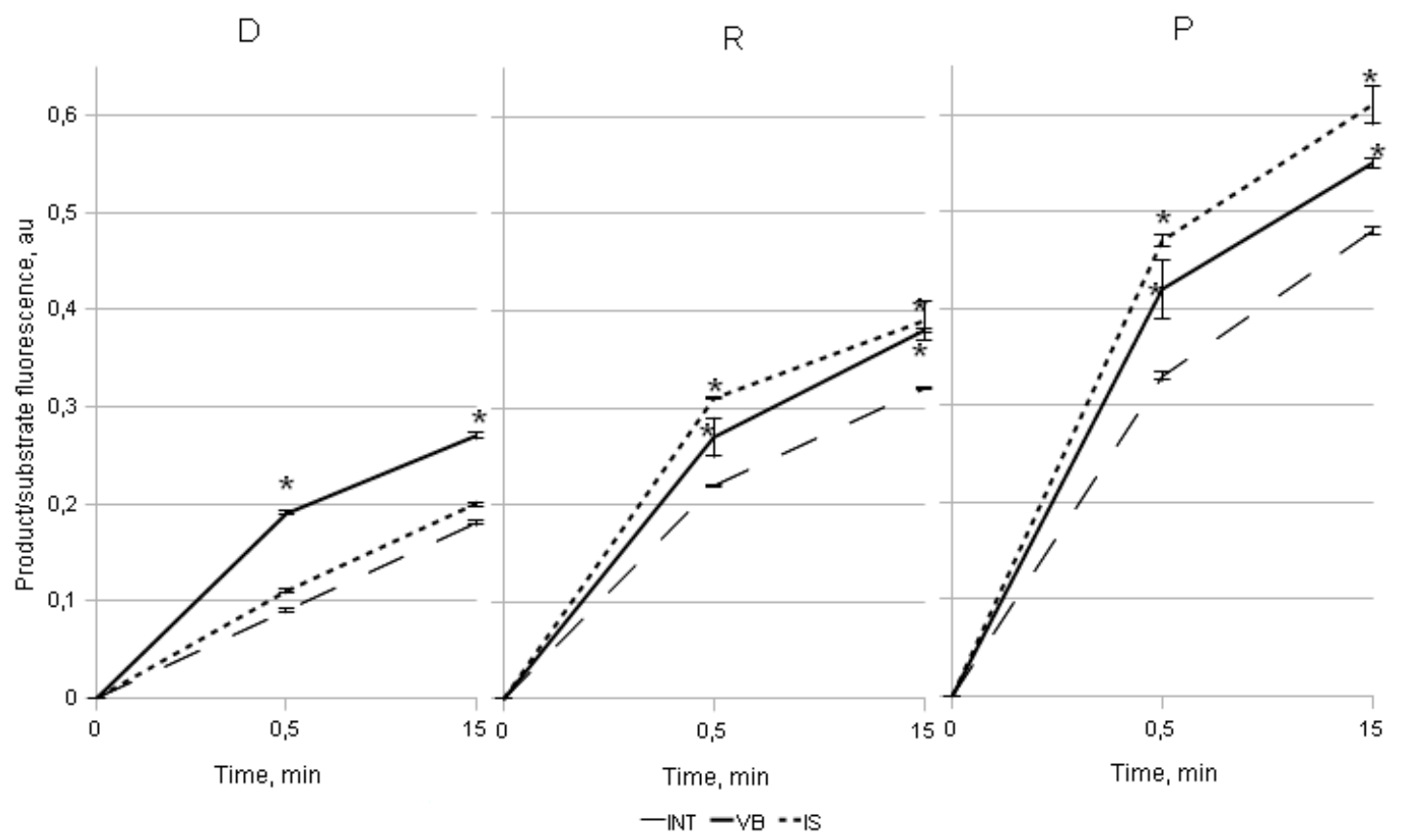

Fig. (3). The influence of vinblastin (VB) and isoniaside (IS) to the intensity of fluorescence of glucuronidase - MUF - $\beta$ - glucuronide cleavage products in the MP supernatants of RA patients $(P, n=24)$, female relatives $(R, n=24)$, and healthy women, not hereditary tainted with autoimmune diseases $(\mathrm{D}, \mathrm{n}=24)(*$ - reliable differences when compared to intact MPs (INT), $\mathrm{p} \leq 0,05)$. 
(Mann-Whitney test, $\mathrm{p}<0,05)$ decrease of the Agg-Ig-FITC engulfment, as compared to the untreated samples - 2,9 times lower in the D cell suspensions $(68,7 \pm 10,2 \mathrm{au}), 3,5$ times lower in the P cell suspensions $(32,3 \pm 3,8$ au) and 3,6 times lower in $\mathrm{R}$ cell suspensions $(31,0 \pm 2,9 \mathrm{au})$, while there was a (ii) reliable (Mann-Whitney test, $\mathrm{p}<0,05)$ rise in the product / substrate fluorescence intensity ratio in all three groups (Fig. 3). These results were rather anticipated since inhibition of enclosed phagosome formation gave rise to the enhancement of lysosomal glucoronidase release.

The influence of isoniazid was revealed only in the $\mathrm{P}$ and $\mathrm{R}$ groups as a reliable (Mann-Whitney test, $\mathrm{p}<0,05$ ) increase of the ratio product/substrate fluorescence intensity ratio in the treated cell samples as compared to those in untreated MP samples (Fig. 3). In the D group there was no influence of isoniazid on the ratio of product/substrate fluorescence intensity in the MP samples, which seems to be natural since lysosomal glucuronidase release following $\mathrm{OZ}$ engulfment by MPs of the Ds primarily occurred into the enclosed phagosomes.

The spontaneous levels of ROS generation (Fig. 4a) by the P $(3,6 \pm 2,1 \mathrm{au})$ and the R (3,5 $\pm 2,6 \mathrm{au})$ MPs were almost twice as much as compared to that in the control group $(1,7 \pm 0,8 \mathrm{au})$, although the difference was found to be nonreliable (Mann - Whitney test, $p>0,05$ ). Total ROS generation in the respiratory burst induced by opsonized zymosan (Fig. 4b) was reliably (Mann - Whitney test, $\mathrm{p}<0,05)$ higher in the Ps $(333,9 \pm 127,9 \mathrm{au})$ than that in the Ds $(76,4 \pm 35,7 \mathrm{au})$, and the highest values were revealed in the Rs $(1197,9 \pm 464,1 \mathrm{au})$. The increased stimulated ROS generation by the MPs of RA patients was anticipated due to the cell priming in chronic rheumatoid inflammation. As to the relatives, we assume that the excessive oxygen radical production in response to MP stimulation may be a result of the pro-inflammatory effect on the cells during frequent and prolonged infectious episodes observed in the RApredisposed relatives [15].

The average serum levels of the cytokines in the P (TNFalpha $82,1 \pm 77,1 \mathrm{pg} / \mathrm{ml}$, IL-1beta $48,8 \pm 31,3 \mathrm{pg} / \mathrm{ml}$ ) and the R

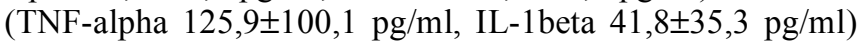
were reliably increased as compared to the controls (TNFalpha $0,9 \pm 0,7 \mathrm{pg} / \mathrm{ml}$, IL - 1beta $0,7 \pm 0,4 \mathrm{pg} / \mathrm{ml}$ ) (Mann Whitney test, $\mathrm{p}<0,05)$. The increased levels of one or both

$$
\text { a) Spontaneous level of ROS generation }
$$

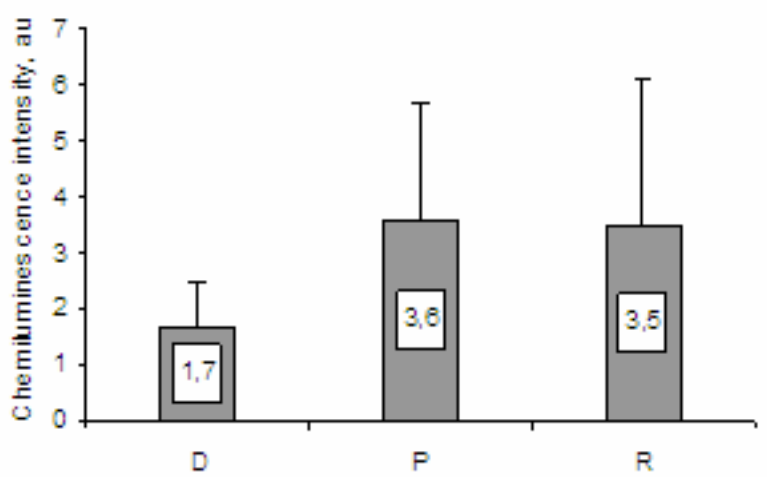

cytokines were revealed in $74 \%$ of the Ps and in $75 \%$ of the Rs and none in the donors. For the Ps the results were anticipated since the high levels of these cytokines are the well known hallmark of the disease $[16,17]$. As to the $R$ group the high levels of pro-inflammatory cytokines - the well known stimulators of the MPs, support our suggestion, that the Rs cells are primed. On the other hand the high levels of these factors may be the signs of the MP activation, at least the circulating monocytes in RA are the main source of serum TNF-alpha and IL-1 [18-22].

No influence of clinical parameter of RA or disease specific therapy on the MP functions under study was found.

\section{DISCUSSION}

The delayed formation of the phagosomes due to the slowed down engulfment of the objects of phagocytosis by the mononuclear phagocytes of the RA patients results in their unclosed form development and in the lysosomal enzyme release into the extracellular environment. This peculiarity of the cell functioning probably resulting in preferentially extracellular digestion seems to be the characteristic feature of the mononuclear phagocytes in RA patients and individuals predisposed to the disease. The cell digestive activity, probably inhibited in predisposed to RA female relatives, becomes abundant after the disease onset; ROS generation by the mononuclear phagocytes is increased both in patients and their relatives.

The delayed engulfment may be due to a RA specific set of expressed membrane receptors. In our experiments we treated the MPs either with Staphylococcus aureus or with zymosan (both of them were opsonized by native serum), or with Agg- IgG-FITC. Thus, in vitro cell stimulation occurred primarily through $\mathrm{Fc}-, \mathrm{C} 3 \mathrm{~b}-$, mannose binding, Toll - like $1,2 / 6$ receptors $[23,24]$; while the cells condition in the two experimental groups was different from that in the control group, as the patient's MPs and probably those of the relatives were primed. The results of many investigations showed that the expression of various MP receptors was adequate to stimuli levels in rheumatoid arthritis both in sera and synovial fluid [25-29]. Thus, one might expect that the increased expression of membrane receptors in patients may result in more rapid and efficient engulfment and digestion. Therefore, in our opinion, the revealed MP functioning

$$
\text { b) Total ROS generation }
$$

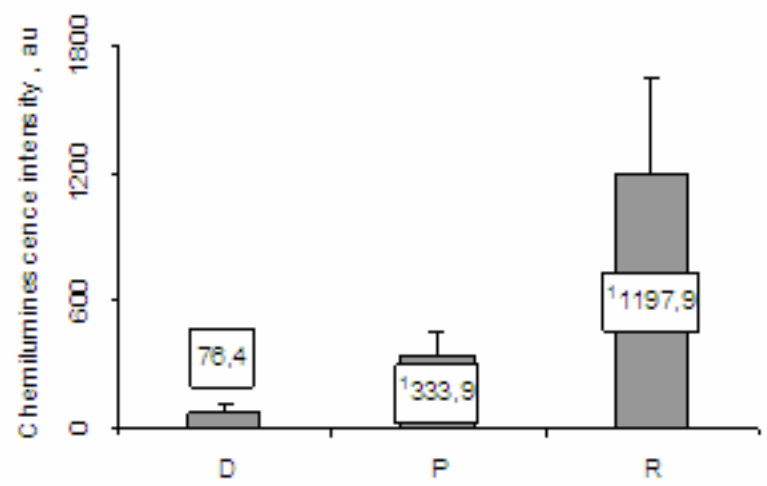

Fig. (4). ROS generation by the MPs of RA patients (P), female relatives (R), and healthy women, not hereditary tainted with autoimmune diseases - donors (D) $\left({ }^{1}\right.$ - reliable difference when compared with D group values (Mann - Whitney criteria)). 
peculiarities in the Ps and, possibly, in the Rs are unlikely to be due to the abnormal membrane receptor sets.

Earlier we tried to analyze whether various MP function activation in RA corresponds to various stimuli levels in vascular bed and joint tissues [30]. The conclusions of the review were the following.

Firs, the main properties of monocytes in the vascular bed in RA are the ongoing priming and chemotaxis towards the sites of inflammation - joint tissues, and arriving to the inflammatory sites they realize their potential as phagocytic and cytotoxic cells. It is well known that the processes of chemotaxis and engulfment are in feedback relationship [31]. In our experiments we picked out the circulating monocytes and placed them in the conditions similar to those in the inflammatory sites by adding aggregated $\operatorname{IgG}$ or opsonized bacteria or zymosan. This sudden change of environment may be a cause of delayed engulfment since the cells have no time enough to reorganize the intracellular machinery from the chemotactic behavior to the phagocytic one.

Second, we assumed that a number of signs in RA can be estimated as manifestation of impaired relationship between some MP separate functions [30]. The discordance of decreased engulfment and enhanced digestion and ROS generation revealed for the MPs in RA is totally consistent with this speculation. This imbalance is probably not true pathologic, since the capacity to express particular functions changes during the cell maturation. For example, immature cells are highly phagocytic but on receiving a maturation stimulus they lose this capacity [24].

On the other hand, there are some data, indicating that impaired relationship between separate MP functions may be due to the altered functioning of the intracellular signal network or plasma membrane. It was shown, for example, that among the "silent" genes in the RA patients there are also genes of some factors, involved in the process of actin polymerization [32]. It is also known, that in RA patients the antibodies to cytoskeletal elements (actin and myosin) are often revealed [33]. Actin is also one of the non-histone targets for histone deacetylases - the enzyme the activity of which is supposed to be impaired in RA patients $[34,35]$.

The other players in the process of phagosome closure are membrane lipids involved in receptor cupping, pseudopod extension and signal transduction [36]. We have already revealed higher viscosity of cellular membrane of the MPs in RA patients and their relatives (unpublished data).

There are some well known remarkable facts. Toll-like receptor mediated cell activation of the cells mainly results in cytokine secretion. Though the expression of these receptors on monocytes is not disturbed in RA, they are known to have higher responsiveness to the ligands, as compared to the cells of osteoarthritis patients and healthy controls [37, 38]. This may be due, for example, to some peculiarities in intracellular signal transduction.

It is also known, that $\mathrm{Fc}$ - receptor mediated phagocytosis is more dependent on actin polymerization and membrane lipid reorganization processes. Thus, taking to consideration the possible problems with actin polymerization and membrane functioning peculiarity together with enhanced responsiveness to the Toll-like receptor stimulation, the revealed changes of the MP functioning in the Ps might be the result of the shift of the cell functions from the process of phagocytosis to cytokine production.

The current experimental series is a part of a long-term (more than 10 years) cohort study of RA and common infections interplay (the results are in press). The dynamic of the annual incidence and duration of the common focal infections was analyzed in groups of 306 RA patients, 242 their first degree female relatives and 214 women not hereditary tainted with autoimmune diseases. It turned out that despite the vigorous suppressive therapy with cytostatics and sometimes with corticosteroids the annual incidence and duration of common infectious episodes in the Ps were close to those in the Ds. At the same time in the R group the focal common infections were 2,1 times more often and 2,6 times more prolonged than that in the control group. In the $\mathrm{R}$ group the infectious syndrome mainly comprised chronic tonsillitis $(51.7 \%)$, exacerbations of which were severe in this group with fever, purulent plugs in tonsils, and in some cases with the peritonsillar abscess development. Purulent bronchitis $(48.3 \%)$, acute respiratory - viral infections $(44.8 \%)$, furunculosis and staphylococcus skin lesion $(27.6 \%)$ were less frequent. Some other focal infections occurred as well: those of otorhinologic organs, of upper respiratory and urinary tracts, the frequency of which was similar to that in Ds.

It should be pointed out that the cell and serum samples were taken from the subjects without any clinical sign of infection in all 3 groups and negative paraclinical markers of inflammation in the Rs and the Ds.

So the data received in the group of prone to RA relatives are rather intriguing. High levels of pro-inflammatory cytokines, presumably, of monocyte origin, and increased stimulated ROS generation may be the signs of prolonged cell activation in the $\mathrm{R}$ group even in the absence of the most probable causes for cell stimulation. Here the delayed engulfment leading to predominantly extracellular digestion due to lysosomal enzyme release into the environment seems to be the specific feature of the MPs in this group as well. Of course it may be due to the nature of cell stimulation, similar to that in RA group. Yet it may be the sign of some hereditary problems in MP functioning as well!

In the predisposed to RA relatives the delayed and suppressed engulfment associated with the decelerated digestive potential of the mononuclear phagocyte may be one of the causes of the infectious syndrome. At the same time in rheumatoid arthritis patients the accelerated digestive potential together with the slowed down process of engulfment and predominantly extracellular digestion may contribute to the massive tissue damage fraught with development of immune reactions to self antigens.

\section{CONCLUSION}

We show for the first time that the functioning of circulating mononuclear phagocytes in the assumed to be healthy predisposed to RA individuals differs from that in the healthy people not hereditary tainted with autoimmune diseases and in general resembles the functioning of the cells in the patients with advanced RA. 


\section{SUMMARY}

Monocyte functions: engulfment, digestion, ROS generation, lysosomal enzyme release into environment, and serum cytokine levels were compared in RA patients and their relatives.

\section{ABBREVIATIONS}

$$
\begin{aligned}
& \text { Agg-Ig-FITC }=\text { FITC-labeled aggregated human } \\
& \text { a.u. } \quad=\text { Arbitrary units } \\
& \mathrm{CPM}=\text { Counts per minute } \\
& \text { Ds } \quad=\text { donors }- \text { Healthy women, not hereditary } \\
& \text { tainted with autoimmune diseases } \\
& \text { HMP }=\text { High molecular weight peptides } \\
& \text { IL-1 } \beta=\text { Interleukin } 1 \text { beta } \\
& \text { LMP }=\text { Low-molecular weight peptides } \\
& \text { MPs }=\text { Mononuclear phagocytes } \\
& \text { OP } \quad=\text { Objects of phagocytosis } \\
& \mathrm{OZ} \quad=\text { Opsonized zymosan } \\
& \text { Ps } \quad=\text { Rheumatoid arthritis patients } \\
& \text { Rs } \quad=\text { First degree maternal female relatives of } \\
& \text { RA patients } \\
& \text { RA = rheumatoid arthritis } \\
& \text { ROS }=\text { Reactive oxygen species } \\
& \text { TNF- } \alpha=\text { Tumor necrosis factor alpha }
\end{aligned}
$$

\section{ACKNOWLEDGEMENTS}

None declared.

\section{CONFLICT OF INTEREST}

None declared.

\section{REFERENCES}

[1] Smeets TJ, Kraan MC, van Loon ME, Tak PP. Tumor necrosis factor alpha blocage reducers the synovial cell infiltrate early after initiation of treatment, but apparently not by induction of apoptosis in synovial tissue. Arthritis Rheum 2003; 48: 2155-62.

[2] Veale D, Yanni G, Rogers S, Barnes L, Breshnihan B, Fitzgerald O. Reduced synovial membrane macrophage numbers, ELAM-1 expression, and lining layer hyperplasia in psoriatic arthritis as compared with rheumatoid arthritis. Arthritis Rheum 1993; 36: 893-900.

[3] Bresnihan B. Are synovial biopsies of diagnostic value? Arthritis Res Ther 2003; 5(6): 271-8.

[4] Ma Y, Pope RM, Kinne RW, et al. The role of macrophages in rheumatoid arthritis. Curr Pharm Des 2005; 11(5): 569-80.

[5] Haringman JJ, Gerlag DM, Zwinderman AH, et al. Synovial tissue macrophages: a sensitive biomarker for response to treatment in patients with rheumatoid arthritis. Ann Rheum Dis 2005; 64(6): 834-8.

[6] Thurlings RM, Wijbrandts CA, Bennink RJ, et al. Monocyte Scintigraphy in Rheumatoid Arthritis: The Dynamics of Monocyte Migration in Immune-Mediated Inflammatory Disease. PLoS One 2009; 4(11): 7865.

[7] Kinne RW, Stuhlmuller B, Burmester GR. Cells of the synovium in rheumatoid arthritis. Macrophages. Arthritis Res Ther 2007, 9: 224.

[8] Kinne RW, Brauer R, Stuhlmuller B, Palombo-Kinne E, Burmester GR. Macrophages in rheumatoid arthritis. Arthritis Res 2000; 2: $189-202$.
Gierut A, Perlman H, Pope RM. Innate immunity and rheumatoid arthritis. Rheum Dis Clin North Am 2010; 36(2): 271-96.

Silva MT. When two is better than one: macrophages and neutrophils work in concert in innate immunity as complementary and cooperative partners of a myeloid phagocyte system. J Leukoc Biol 2010; 87(1): 93-106.

[11] Silman AJ, Pearson JE. Epidemiology and genetics of rheumatoid arthritis. Arthritis Res 2002; 4(3): 265-72.

[12] Kinne RW, Rolf B, Stuhlmuller B, Palombo-Kinne E, Burmester GR. Macrophages in rheumatoid arthritis. Arthritis Res 2000; 2: 189-202.

[13] Duglas SD, Kui PG. Investigation into Phagocytosis in the Clinical Practice. Moscow: Medicina 1993.

[14] Schmidtke JR, Unanue ER. Macrophage - antigen interaction Uptake, metabolism and immunogenicity of foreign albumin. J Immunol 1971; 107(2): 331-8.

[15] Arleevskaya MI, Shilkina NP, Tsybulkin AP. Clinical and laboratory signs of disturbed functioning of the immune system in rheumatoid patients and their genetic relatives. Ther Arch 2005; 5: 83-6 (in Russian).

[16] Paramalingam SP, Thumboo J, Vasoo S, Thio ST, Tse C, Fong KY. In vivo pro- and anti-inflammatory cytokines in normal and patients with rheumatoid arthritis. Ann Acad Med Singapore 2007; 36(2): 969.

[17] Feldmann M, Brennan FM, Maini RN. Role of cytokines in rheumatoid arthritis. Annu Rhev Immunol 1996; 14: 397-440

[18] Leirisalo RM, Paimela| L, Jäätteä| M, Koskimies S, Repo H. Production of TNF by Monocytes of Patients with Early Rheumatoid Arthritis is Increased. Scan J Rheumatol 1995; 24(6): 366-71.

[19] Wood NC, Dickens E, Symons JA, Duff GW. In situ hybridization of interleukin-1 in CD14-positive cells in rheumatoid arthritis. Clin. Immunol. Immunopathol 1992; 62: 295-300.

[20] Hahn G, Stuhlmuller B, Hain N, Kalden JR, Pfizenmaier K, Burmester GR. Modulation of monocyte activation in patients with rheumatoid arthritis by leukapheresis therapy. J Clin Invest 1993; 91: 862-870.

[21] Schulze KH, Davis LS, Kavanaugh AF, Lipsky PE. Elevated cytokine messenger RNA levels in the peripheral blood of patients with rheumatoid arthritis suggest different degrees of myeloid cell activation. Arthritis Rheum 1997; 40: 639-47.

[22] Szekanecz Z, Koch AE. Macrophages and their products in rheumatoid arthritis. Curr Opin Rheumatol 2007; 19(3): 289-95.

[23] Liote F, Boval BB, Weill D, Kuntz D, Wautier JL. Blood monocyte activation in rheumatoid arthritis: Increased monocyte adhesiveness, integrin expression, and cytokine release. Clin Exp Immunol 1996; 106: $13-9$.

[24] Jack RM, Fearon DT. Altered surface distribution of both C3b receptors and $\mathrm{Fc}$ receptors on neutrophils induced by anti-C3b receptor or aggregated IgG. J Immunol 1984; 32(6): 3028-33.

[25] Stuart LM, Ezekowitz AB. Phagocytosis: Elegant Complexity. Immunity $2005 ; 22: 539-50$.

[26] Torsteinsdottir I, Ardvison NG, Hallgren R, Hakansson L. Monocyte activation in rheumatoid arthritis (RA): increased integrin, Fc $\gamma$ and complement receptor expression and the effect of glucocorticoids. Clin Exp Immunol 2001; 115(3): 554-60.

[27] Brentano F, Kyburz D, Gay S. Toll-like receptors and rheumatoid arthritis. Methods Mol Biol 2009; 517: 329-43,

[28] Huang Q, Ma Y, Adebayo A, Pope R.M. Increased macrophage activation mediated through toll-like receptors in rheumatoid arthritis. Arthritis Rheum 2007; 56(7): 2192-201

[29] Aita T, Okamoto A, Ueno A, et al. Expression of Toll-like receptor 2 on $\mathrm{CD} 16+$ blood monocytes and synovial tissue macrophages in rheumatoid arthritis. Arthritis Rheum 2004; 50(5): 1457-67.

[30] Arleevskaya MI, Tsyboolkin AP. Rheumatoid arthritis as a pathology of monocyte-macrophage system. Immunologia 1997; 6: $62-7$ (in Russian).

[31] Luo Y, Isaac BM, Casadevall A, Cox D. Phagocytosis Inhibits FActin-Enriched Membrane Protrusions Stimulated by Fractalkine (CX3CL1) and Colony-Stimulating Factor 1. Infec Immun 2009; 77(10): 4487-95.

[32] Olsen NJ, Sokka T, Seehorn CL, et al. A gene expression signature for recent onset rheumatoid arthritis in peripheral blood mononuclear cells. Ann Rheum Dis 2004; 63: 1387-92.

[33] Shrivastav M, Mittal B, Aggarwal A, Misra R. Autoantibodies against cytoskeletal proteins in rheumatoid arthritis. Clin Rheumatol 2002; 21(6): 505-510. 
[34] Glozak MA, Sengupta N, Zhang X, Seto E. Acetylation and deacetylation of non-histone proteins. Gene 2005; 363: 15-23.

[35] Strietholt S, Maurer B, Peters MA, Pap T, Gay S. Epigenetic modifications in rheumatoid arthritis. Arthritis Res Ther 2008; 10: 219.

[36] Steinberg BE, Grinstein S. Pathogen destruction versus intracellular survival: the role of lipids as phagosomal fate determinants. J. Clin Invest 2008; 118(6): 2002-11.
[37] Banks ER, Whicher JT, Thompson D, Bird HA. Acute phase response. In: Maddison PJ, Isenberg DA, Woo P, Glass DN, Eds. Oxford Textbook of Rheumatology. UK: Oxford University Press 1998; 1: pp. 623-31.

[38] Kowalski ML, Wolska A, Grzegorczyk J, et al. Increased Responsiveness to Toll-Like Receptor 4 Stimulation in Peripheral Blood Mononuclear Cells from Patients with Recent Onset Rheumatoid Arthritis. Mediators Inflammation 2008; Article ID 132732 .

Received: June 30, 2011

Revised: July 30, 2011

Accepted: August 3, 2011

(C) Arleevskaya et al.; Licensee Bentham Open.

This is an open access article licensed under the terms of the Creative Commons Attribution Non-Commercial License (http://creativecommons.org/licenses/ by-nc/3.0/) which permits unrestricted, non-commercial use, distribution and reproduction in any medium, provided the work is properly cited. 